\title{
Including Cash Flow Risk In Stock Return Analysis
}

Janet West, Colorado College, USA

Judy Laux, Colorado College, USA

\begin{abstract}
Despite their prominence in financial theory and practice, the Capital Asset Pricing Model and its critical beta component have failed test after test to explain stock returns. Research by Campbell and Vuolteenaho cites the misspecification of beta as the reason for this failure. They measure beta as the sum of two components: a more influential "cash-flow" beta and a secondary "discount-rate" beta. The current study creates a ratio between the overall beta of a stock and the cash-flow component and uses an ordinary least squares regression model to determine its significance in interpreting overall returns to a stock, hypothesizing that the ratio will better explain returns than the overall beta alone. The results are mixed but suggest significant explanatory power for the beta range of 0.60 to 0.95 .
\end{abstract}

Keywords: CAPM, beta, cash-flow

\section{INTRODUCTION}

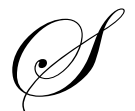

ince its introduction in the 1960s, the capital asset pricing model (CAPM) has revolutionized the financial world. The model provides a simple and intuitive method to determine how a portfolio is doing given its systematic risk, citing beta as the only relevant factor in predicting returns. This relatively straightforward approach is one of the reasons for the CAPM's continued popularity today. Additionally, the CAPM has worked its way into the world of corporate finance as the preferred method taught in MBA courses. In short, investors and financial managers are still relying on this simple model to make key investment decisions.

While the beta measure and CAPM are considered to be cornerstones of financial theory, researchers continue to challenge the abilities of these models from all angles. Replications of the model on more recent data have failed nearly every time to explain returns. The continued use of the model in practice despite its failures can have negative implications for both investors relying on the model to evaluate stock performance as well as financial managers using the model to evaluate large investment projects for their firms.

The purposes of this study are to challenge the traditional beta and to evaluate the usefulness of a ratio that uses the relationship between the overall beta of a stock and its cash-flow component to measure the risk-return relationship. Building on the work of Campbell and Vuolteenaho [2004], this paper attempts to provide an alternative method for stock analysis that might allow investors to compare the risk of different stocks with more accuracy. Because of this unique way of looking at the components of beta, this research should also provide financial managers a better alternative in evaluating capital budgeting projects. The first part of the study presents some of the relevant literature related to beta and the CAPM as well as the importance of cash-flow to stock returns. The rest of the paper details the research and analysis performed to evaluate the effectiveness of the overall beta to cash-flow beta ratio in explaining stock returns.

\section{A BRIEF REVIEW OF THE LITERATURE}

The Capital Asset Pricing Model (CAPM) was introduced independently by William Sharpe and John Lintner in 1964 and 1965, respectively. This model uses beta, a measure of the systematic risk of a security, to determine the required return for holding that security, and the measure has played a key role in many aspects of 
investments. While it has become one of the primary models for evaluating portfolio performance as well as estimating the cost of capital in corporate finance, it has also been the subject of many tests of validity and reliability. Much of the CAPM critique relates to the use of beta as the only important factor when evaluating risk and return. Research by Chan, Hamao, and Lakonishok (1991) and Fama and French (1992 and 2004) has shown that other factors not included in beta (such as book-to-market ratio, cash-flow yield, and size) may also influence returns, indicating there may be more to returns than beta alone can justify, or as is suggested by Campbell and Vuolteenaho (2004), more than beta can correctly specify.

Campbell and Vuolteenaho look at the returns on market portfolios as a factor of two components rather than the one offered by beta and the CAPM, arguing that beta is misspecified rather than incorrect. Instead of trying to capture systematic risk in one factor, that measure should be the sum of a cash flow beta and a discount rate beta, thus giving proper weights of risk to each component. News about future cash flows is important to an investor because it affects future dividend growth, which is then reflected in the stock price. News about discount rates also moves stock prices, since changing the discount rate that a firm applies to its cash flows alters the price of its stock. Both factors carry a certain amount of risk; however, as negative cash flow news does not present any new opportunities for future investment, it contains the higher amount of risk. An investor will only see a loss of wealth when dividends or the rate of dividend growth decreases, whereas an increase in the discount rate, while bad for wealth, also presents better opportunities for future investments.

Though Campbell and Vuolteenaho choose to decompose overall beta into a cash-flow beta and a discountrate beta, the significance of cash-flows to stock returns is not a new idea. Already mentioned is the Chan et al. study of the Japanese markets and the importance of cash-flow yields in explaining stock returns, suggesting cash flows hold relevance to the market. In addition, Campbell (1991), prior to researching and writing "Bad Beta, Good Beta," used a log-linear dividend ratio model to decompose the behavior of the New York Stock Exchange Index into future cash flow and future expected returns. He found that, though not independent of one another, both played an explanatory role in describing the variance of unexpected stock returns. Vuolteenaho (2002) later took these results to determine the impact on the firm level and found that the most important factor influencing individual firm returns was news about cash-flows, with over twice as much power in explaining returns as that of discount rates.

Much of the research involving cash-flow news and decomposition revolves around understanding the anomaly that exists between value and growth stocks or large and small stocks. The current paper extends this research by including all stocks, grouping stocks by beta levels, and using a beta ratio to measure the relationship between risk and return. This investigation holds relevance for both stock valuation and cost of capital estimation.

\section{METHODOLOGY}

This paper investigates the usefulness of the cash-flow beta's significance in explaining returns by creating a ratio between the overall beta of a firm and its associated cash-flow beta. It is tested against the returns of the firm to determine if any explanatory power exists in this financial ratio. Firms are placed into groups with similar overall betas to detect if the magnitude of the ratio has any explanatory power on returns to the firm. If the results suggest this relationship better explains returns, investors and financial managers might make better investment decisions.

Historical betas were calculated in a manner similar to Value Line by regressing each stock's weekly returns over a five-year time period against the returns of the market, proxied in this paper by the S\&P 500 returns. The method used in calculating the cash-flow beta closely follows the research performed by Cohen, Polk, and Vuolteenaho in their forthcoming article entitled, "The Price is (Almost) Right." These authors measure the cashflow beta by using an ordinary least squares regression to model a firm's profitability against that of the market. In this case, profitability is measured through a discounted log return on equity for both the stock and the market, as seen in the following model: 


$$
\sum_{j=0}^{N-1} \rho^{j} \log \left(1+R O E_{k, t+j, j+1}\right)=\beta_{k, 0}^{C F}+\beta_{k, 1}^{C F} \sum_{j=0}^{N-1} \rho^{j} \log \left(1+R O E_{M, t+j}\right)+\varepsilon_{k, t+N-1}
$$

Here $\mathrm{k}$ refers to the stock, $\mathrm{M}$ refers to the market, $\mathrm{t}+\mathrm{j}$ is the year of observation, and $\boldsymbol{p}$ is the discounting factor equal to one minus the average dividend yield. The variable $\boldsymbol{p}$ is a constant, a number the authors calculate to equal $0.975,{ }^{1}$ which will also be used as the discount factor for the purposes of this paper. ${ }^{2}$ The historical beta for each stock was then divided by its corresponding cash-flow beta to create the ratio between them. Campbell and Vuolteenaho's (2004) research has shown that a higher cash-flow beta should provide additional returns because of the associated risk. Thus, a smaller ratio between the overall beta and cash-flow beta should imply the same thing, because the denominator would be larger the higher the cash-flow risk component.

To test the theory that stock performance and market beta to cash-flow beta ratio are related, the following ordinary least squares regression was used:

$$
\begin{gathered}
\text { Return }_{\mathrm{t}}=\beta_{0}+\beta_{1} \mathrm{OB}_{\mathrm{t}}+\beta_{2} \mathrm{OB}_{\mathrm{t}-1}+\beta_{3} \mathrm{CFB}_{\mathrm{t}}+\beta_{4} \mathrm{CFB}_{\mathrm{t}-1}+\beta_{5} \mathrm{R}_{\mathrm{t}}+\beta_{6} \mathrm{R}_{\mathrm{t}-1}+\beta_{7}\left(\mathrm{R}_{\mathrm{t}}\right)^{2} \\
+\beta_{8}\left(\mathrm{R}_{\mathrm{t}-1}\right)^{2}+\beta_{9} \mathrm{Y}_{2007}+\beta_{10} \mathrm{Y}_{2006}+\beta_{11} \mathrm{Y}_{2005}
\end{gathered}
$$

Return refers to the return on stock for the period including dividends, OB refers to the overall calculated beta for the period, CFB refers to the calculated cash-flow beta for the period, and R refers to the ratio between overall beta and cash-flow beta. Also included are three dummy variables related to the year from which the data were taken to account for any year-related characteristics for returns.

\section{DATA}

The 120 stocks for the sample were chosen according to their most recent beta listed on Yahoo! Finance. The selection included thirty randomly selected firms grouped into four categories: Those with betas ranging from 0.49 to $.51,0.99$ to $1.01,1.49$ to 1.51 , and 1.98 to 2.02 . Beta and pricing data were collected and calculated for analysis over a five-year time period. For each year, the entire group of 120 stocks was pooled together, sorted according to their overall betas, and divided into four new groups. Negative numbers were sorted according to absolute value so they would be placed in the group with a similar quantity of risk, despite the opposite movement in relation to the market. ${ }^{3}$ This also prevents them from being grouped into a category of low beta stocks. Group I consists of stocks with betas less than or equal to 0.60 , Group II with betas between 0.60 and 0.95 , Group III with betas between 0.95 and 1.25, Group IV with betas greater than 1.25. The formation of these new groups permits comparison of the overall beta to cash-flow beta ratio with returns for firms within the same beta group.

\section{RESULTS AND ANALYSIS}

The first group covers firms with a beta less than or equal to 0.60 over the years 2007 back to 2004 . Table 1 summarizes these results. ${ }^{4}$ The $\mathrm{R}^{2}$ value of 0.1718 indicates that the full model is able to explain $17.18 \%$ of the variation in the data. A better measure of fit, however, is the adjusted $\mathrm{R}^{2}$ value of $8.5 \%$, meaning that for Group $\mathrm{I}$, the full model is a poor fit. The t-statistics agree, as only one coefficient - that for the year 2007—can be proven to be significantly different from zero. Removing some of the insignificant variables failed to improve the model.

\footnotetext{
${ }_{2}^{1} \rho \square$ relates the average consumption-wealth ratio, or how much is reinvested after consumption

2 The sample of firms and overall and cash-flow beta calculations are available from the authors upon request.

3 As indicated in the Results and Analysis section, this caused some uncertainty in interpretation of the direction of the cash-flow and ratio signs.

${ }^{4}$ All tables appear at the end of this article.
} 
Table 1

Full Model Ordinary Least Squares Regression for Group I (Overall Beta Less Than or Equal to 0.60)

\begin{tabular}{|c|c|c|}
\hline \multicolumn{3}{|c|}{ Group I } \\
\hline Variable & Coefficient & T-statistic \\
\hline $\mathbf{C}^{\mathrm{a}}$ & 0.0864 & 1.600 \\
\hline Overall beta ${ }_{t}^{b}$ & 0.4122 & 1.554 \\
\hline Overall beta $_{t-1}$ & -0.2605 & -0.868 \\
\hline Cash-flow beta ${ }_{t}^{c}$ & 0.0151 & 1.543 \\
\hline Cash-flow beta t-1 $_{\text {. }}$ & 0.0076 & 0.566 \\
\hline Ratio $_{\mathbf{t}}^{\mathbf{d}}$ & -0.0119 & -1.039 \\
\hline Ratio $_{t-1}$ & 0.0018 & 0.177 \\
\hline$\left(\text { Ratio }_{t}\right)^{2}$ & 0.0003 & 1.431 \\
\hline$\left(\text { Ratio }_{t-1}\right)^{2}$ & 0.0001 & 0.311 \\
\hline Year $_{2007}{ }^{\mathrm{e}}$ & -0.1902 & $-3.196 * * *$ \\
\hline Year $_{2006}$ & -0.0958 & -1.634 \\
\hline Year $_{2005}$ & -0.0317 & -0.539 \\
\hline \multicolumn{3}{|c|}{$\begin{array}{l}\mathrm{R}^{2}=0.1718 \\
\text { Adjusted } \mathrm{R}^{2}=0.0850 \\
\text { Breusch-Godfrey Statistic }=5.340 * * \\
\text { White Statistic }=35.54 * * *\end{array}$} \\
\hline \multicolumn{3}{|c|}{$\begin{array}{l}\text { * Indicates results at the } 90 \% \text { confidence level } \\
\text { ** Indicates results at the } 95 \% \text { confidence level } \\
\text { *** Indicates results at the } 99 \% \text { confidence level } \\
\text { a Refers to the intercept term of the regression } \\
\text { b The beta of the stock: relates movements in a stock price to the movements in the market } \\
{ }^{\mathrm{c}} \text { Relates cash-flow risk of a firm to that of the market } \\
\text { d The ratio of overall (total) beta to cash-flow beta } \\
\text { e Dummy variable taking on a value of } 1 \text { if stock data are taken from that year, and } 0 \text { otherwise }\end{array}$} \\
\hline
\end{tabular}

The second group covers the regression for those stocks with betas between 0.60 and 0.95 . The results follow in Table 2. Contrary to Group I, Group II fits nicely with the full model. With an $\mathrm{R}^{2}$ of over $50 \%$ and adjusted value of $46 \%$, clearly the variables as a whole contribute significantly to the regression equation even if individually all are not found to be significant. However, the sign on the cash-flow beta is as anticipated in period $t$ but not in t-1, perhaps the result of grouping stocks with negative betas together with those with positive betas of equal amplitude (See footnote 3.) An improved model is also detailed in Table 2. This new model increases the adjusted $\mathrm{R}^{2}$ term by $2 \%$ to $48.22 \%$. More importantly, with the exception of the year variable, all terms are statistically significant at the individual level.

The model for Group III investigates returns for firms with betas between .95 and 1.25. The results from the regression are located in Table 3. The results of the model for this group are similar to the outcome for Group I, in that the full model has no individually significant variables. The $\mathrm{R}^{2}$ term is a very mediocre $17.94 \%$ with the adjusted term an even more disappointing 7.44\%, representing another poor fit. The restricted model, cutting out all variables except overall beta for the period t-1 and the years 2007 and 2005, only slightly improves the adjusted $\mathrm{R}^{2}$ term to $8.32 \%$. 
Table 2

Full Model and Optimal Model Ordinary Least Squares Regression for Group II (Overall Beta 0.60 to 0.95 )

\begin{tabular}{|c|c|c|c|c|}
\hline \multicolumn{5}{|c|}{ Group II } \\
\hline \multirow[t]{2}{*}{ Variable } & \multicolumn{2}{|c|}{ Full Model } & \multicolumn{2}{|c|}{ Optimal Model } \\
\hline & Coefficient & T-Statistic & Coefficient & T-Statistic \\
\hline $\mathbf{C}$ & 0.2472 & 1.592 & 0.2138 & $5.211 * * *$ \\
\hline Overall beta $_{t}$ & -0.1528 & -0.580 & -- & -- \\
\hline Overall beta $_{t-1}$ & 0.1665 & 0.940 & -- & -- \\
\hline Cash-flow beta ${ }_{t}$ & 0.0351 & $2.456^{*}$ & 0.0344 & $2.493 * *$ \\
\hline Cash-flow beta ${ }_{t-1}$ & -0.0285 & $-1.802 *$ & -0.0273 & $-1.841^{*}$ \\
\hline Ratio $_{t}$ & -0.0211 & $-6.180 * * *$ & -0.0216 & $-6.512 * * *$ \\
\hline Ratio $_{t-1}$ & -0.0011 & 0.324 & -- & -- \\
\hline$\left(\text { Ratio }_{t}\right)^{2}$ & 0.0004 & $8.059 * * *$ & 0.0004 & $8.329 * * *$ \\
\hline$\left(\text { Ratio }_{t-1}\right)^{2}$ & $-1.11 \mathrm{E}-05$ & -0.213 & -- & -- \\
\hline Year $_{2007}$ & -0.064311 & -0.5990111 & -- & -- \\
\hline Year $_{2006}$ & -0.0323 & -0.343 & -- & -- \\
\hline Year $_{2005}$ & -0.1542 & -1.614 & -0.1103 & -1.513 \\
\hline \multicolumn{2}{|c|}{$\begin{array}{l}\text { Full Model } \\
\mathrm{R}^{2}=0.5205 \\
\text { usted } \mathrm{R}^{2}=0.4606 \\
\text { odfrey Statistic }=.0005 \\
\text { Statistic }=13.088\end{array}$} & & \multicolumn{2}{|c|}{$\begin{array}{c}\text { Optimal Model } \\
\mathrm{R}^{2}=.5039 \\
\text { Adjusted } \mathrm{R}^{2}=.4822 \\
\text { Breush-Godfrey Statistic }=0.0006 \\
\text { White Statistic }=2.530\end{array}$} \\
\hline \multicolumn{5}{|c|}{$\begin{array}{l}* \quad \text { Indicates results at the } 90 \% \text { confidence level } \\
* * \quad \text { Indicates results at the } 95 \% \text { confidence level } \\
* * * \text { Indicates results at the } 99 \% \text { confidence level }\end{array}$} \\
\hline
\end{tabular}

The final test investigated firms with betas greater than 1.2. The results from this regression are found in Table 4. Much like the first and third regressions, there is little significance in this data subset using the full model. The variables provide limited contribution to the regression as noted by the $\mathrm{R}^{2}$ value of $14.85 \%$ and adjusted value of $5.67 \%$; the model is a very poor one. The reduced equation keeps only the variables for overall beta in time $t$ and cash-flow beta in time $\mathrm{t}-1$ in addition to the year 2007 variable. Interestingly enough, the new adjusted $\mathrm{R}^{2}$ term after the removal of those variables nearly doubles (to 10.37\%) the variance explained by the model. This is a significant improvement over the full model, though none of the individual variables is statistically significant.

An investigation of the regression for the full sample of firms showed no overall significance, ${ }^{5}$ which helps to justify the grouping of the data. The results from the entire sample showed the least explanatory power with the lowest $\mathrm{R}^{2}$ values of the ten regressions performed. One might surmise that groups of stocks with similar overall beta values have their own unique characteristics that cannot be generalized over a full sample. The improved explanation of variation with each subsample, Groups I through IV, when compared to the overall regression, helps to support this interpretation.

A notable observation is the lack of a significant cash-flow variable, though it did appear as the only significant variable when analyzing the full sample of data. Since the ratio already contains some aspect of the cashflow risk, this might explain why the cash-flow measure fails to appear as a separate significant variable in some of the equations. It could also be something that is unique when making an inference about an entire group of firms

5 The regression model for the whole sample performed poorly, with an $\mathrm{R}^{2}$ of only $7.63 \%$ and an adjusted value of $5.42 \%$. 
with non-similar overall betas. When the data were grouped by overall beta, the cash-flow beta did not always make an appearance as a significant variable, however when the entire sample was tested, the cash-flow beta proved to be more significant than overall beta when explaining that year's returns.

Table 3

Full Model Ordinary Least Squares Regression for Group III (Overall Beta 0.95 to 1.25)

\begin{tabular}{|c|c|c|c|c|}
\hline \multicolumn{5}{|c|}{ Group III } \\
\hline \multirow[t]{2}{*}{ Variable } & \multicolumn{2}{|c|}{ Full Model } & \multicolumn{2}{|c|}{ Optimal Model } \\
\hline & Coefficient & T-statistic & Coefficient & T-statistic \\
\hline $\mathbf{C}$ & 0.1220 & 1.307 & 0.1606 & 0.173 \\
\hline Overall beta $_{t}$ & 0.0716 & 0.442 & - & - \\
\hline Overall beta $_{t-1}$ & -1.698 & -1.002 & -0.1155 & 0.259 \\
\hline Cash-flow beta ${ }_{t}$ & 0.0044 & 0.406 & - & - \\
\hline Cash-flow beta t-1 & 0.0071 & 0.743 & - & - \\
\hline Ratio $_{t}$ & -0.0084 & -0.634 & - & - \\
\hline Ratio $_{t-1}$ & -0.0046 & -0.370 & - & - \\
\hline$\left(\text { Ratio }_{t}\right)^{2}$ & $-5.89 \mathrm{E}-05$ & -0.496 & - & - \\
\hline$\left(\text { Ratio }_{\mathrm{t}-1}\right)^{2}$ & $-8.37 \mathrm{E}-05$ & -0.730 & - & - \\
\hline Year $_{2007}$ & -0.1430 & -1.491 & -0.1367 & 0.109 \\
\hline Year $_{2006}$ & -0.0161 & -0.151 & - & \\
\hline Year $_{2005}$ & -0.1537 & 1.572 & 0.1774 & 0.0561 \\
\hline \multicolumn{2}{|c|}{$\begin{array}{c}\text { Full Model } \\
\mathrm{R}^{2}=0.1794 \\
\text { Adjusted } \mathrm{R}^{2}=0.0744 \\
\text { Breusch-Godfrey Statistic }=.9102 \\
\text { White Statistic }=55.393^{* * *}\end{array}$} & & \multicolumn{2}{|c|}{$\begin{array}{c}\text { Optimal Model } \\
\mathrm{R}^{2}=0.1116 \\
\text { Adjusted } \mathrm{R}^{2}=0.0832 \\
\text { Breusch-Godfrey Statistic }=0.6599 \\
\text { White Statistic }=2.563\end{array}$} \\
\hline \multicolumn{5}{|c|}{$\begin{array}{l}* \quad \text { Indicates results at the } 90 \% \text { confidence level } \\
* * \text { Indicates results at the } 95 \% \text { confidence level } \\
* * * \text { Indicates results at the } 99 \% \text { confidence level }\end{array}$} \\
\hline
\end{tabular}

Overall, the most successful model was that for Group II, for both the full and optimal models, consistent with expectations and the hypothesis. It also represents the only model for which neither autocorrelation nor serial correlation (as indicated by the Breusch-Godfrey statistic) displayed significant problems. In addition, of the four groups tested, the second group had the highest $\mathrm{R}^{2}$ term and the best fit with the data set. However, three of the four datasets did not even find the ratio between overall beta and cash-flow beta significant to the equation, though it was significant for Group II. The results of this study might relate to the differences in betas. Perhaps the 0.60 to 0.95 range of beta is a more stable range, and moving farther and farther away in either direction decreases the descriptive power of the ratio between overall beta and cash-flow beta. It might be inferred that this regression works best in a mid range of betas that extends neither extremely high nor extremely low. 
Table 4

Full Model Ordinary Least Squares Regression for Group IV

(Overall Beta Greater than 1.25)

\begin{tabular}{|c|c|c|c|c|}
\hline \multicolumn{5}{|c|}{ Group IV } \\
\hline \multirow[t]{2}{*}{ Variable } & \multicolumn{2}{|c|}{ Full Model } & \multicolumn{2}{|c|}{ Optimal Model } \\
\hline & Coefficient & T-Statistic & Coefficient & T-Statistic \\
\hline $\mathbf{C}$ & -0.0321 & -0.087 & 0.0020 & 0.006 \\
\hline Overall beta $_{t}$ & 0.1055 & 0.348 & 0.1244 & 0.699 \\
\hline Overall beta $_{t-1}$ & 0.0399 & 0.163 & -- & -- \\
\hline Cash-flow beta & -0.0087 & -0.614 & -- & -- \\
\hline Cash-flow beta t-1 & 0.0335 & $2.917 * * *$ & 0.0325 & 1.301 \\
\hline Ratio $_{t}$ & 0.0062 & -0.726 & -- & -- \\
\hline Ratio $_{t-1}$ & 0.0008 & 0.085 & -- & -- \\
\hline$\left(\text { Ratio }_{t}\right)^{2}$ & $5.63 \mathrm{E}-05$ & 0.723 & -- & -- \\
\hline$\left(\text { Ratio }_{t-1}\right)^{2}$ & $-3.75 \mathrm{E}-05$ & -0.464 & -- & -- \\
\hline Year $_{2007}$ & -0.3120 & -1.680 & -0.3394 & $-2.087 * *$ \\
\hline Year $_{2006}$ & 0.0721 & 0.364 & -- & -- \\
\hline Year $_{2005}$ & -0.0899 & 0.442 & -- & -- \\
\hline \multicolumn{3}{|c|}{$\begin{array}{c}\text { Full Model } \\
\mathrm{R}^{2}=0.1485 \\
\text { Adjusted } \mathrm{R}^{2}=0.0567 \\
\text { Breusch-Godfrey Statistic }=.0299 \\
\text { White Statistic }=27.251\end{array}$} & \multicolumn{2}{|c|}{$\begin{array}{c}\text { Optimal Model } \\
\quad \mathrm{R}^{2}=0.1275 \\
\text { Adjusted } \mathrm{R}^{2}=0.1037 \\
\text { Breusch-Godfrey Statistic }=.0371 \\
\text { White Statistic }=20.977 * * *\end{array}$} \\
\hline \multicolumn{5}{|c|}{$\begin{array}{l}* \quad \text { Indicates results at the } 90 \% \text { confidence level } \\
* * \text { Indicates results at the } 95 \% \text { confidence level } \\
* * * \text { Indicates results at the } 99 \% \text { confidence level }\end{array}$} \\
\hline
\end{tabular}

\section{CONCLUSION}

This paper examined the relationship between the cash-flow beta of a firm and its returns using the ratio between overall and cash-flow beta. The results showed a statistically significant relationship between returns and the beta to cash-flow beta ratio for the overall beta category .60 to .95 (Group II). The cash-flow beta was also statistically significant for this group, however the direction of the relationship was not as anticipated at $t-1$. The other beta categories did not provide any statistically significant results, though overall beta did turn out to be a better explanatory variable for the other three groups than either the cash flow beta or the ratio between the two betas. Thus, this research finds that the hypothesis of a significant relationship between returns and the ratio of the total beta to the cash-flow beta component only stands for firms with overall betas that are neither extremely high nor extremely low, suggesting potential usefulness for the more conservative investor or financial manager. For stocks with betas outside the range of Group II, the overall beta remains the more reliable measure of risk and return for this study.

This study, however, is not without its limitations. First of all, the sample size was quite limited in its 120 firms (in groups of 30) and five-year period. Additionally, the lack of fit in the regression model for all but one category suggests there may be other factors explaining stock returns that are not included in this model. This thesis provides a nice starting point from which to develop further insights; future research might benefit from expanding the time horizon and including more firms or expanding the beta groupings, especially in the .60 to .95 beta range. The search should continue for a better way to analyze the risk-return relationship, both to analyze stock performance and to aid financial managers in more correctly determining the cost of equity capital for their firms. 


\section{AUTHOR INFORMATION}

Janet West is a 2009 Mathematical Economics graduate from Colorado College whose senior thesis provided the basis for this work.

Judy Laux is a Gerald L. Schlessman Professor of Economics and Business at Colorado College, teaching and researching in the areas of accounting and finance.

\section{REFERENCES}

1. Campbell, J., 1991. “A Variance Decomposition for Stock Returns,” The Economic Journal, 101, 157-179.

2. $\quad$ Campbell, J., Vuolteenaho, T., 2004. "Bad Beta, Good Beta." The American Economic Review, 94, 12491275.

3. Chan, L., Hamao, Y., and Lakonishok, J., 1991. "Fundamentals and Stock Returns in Japan." The Journal of Finance, 46, 1739-1764.

4. Cohen, R., Polk, C., and Vuolteenaho, T., forthcoming. "The Price is Almost Right.” Journal of Finance.

5. $\quad$ Fama, E.and French, K., 2004. "The Capital Asset Pricing Model: Theory and evidence." The Journal of Economic Perspectives, 18, 25-46.

6. _. 1992. "The Cross-Section of Expected Stock Returns." The Journal of Finance, 47, 427465.

7. Sharpe, W., 1964. "Capital asset prices: A theory of market equilibrium under conditions of risk." Journal of Finance, 19, 425-442.

8. Vuolteenaho, T., 2002. "What Drives Firm-Level Stock Returns?” Journal of Finance, 57, 233-264. 